\title{
O USO DA HISTÓRIA DA MATEMÁTICA NA APROPRIAÇÃO DO CONCEITO DE NÚMERO: UM ESTUDO COM ALUNOS SURDOS DA EJA
}

\author{
Thamires Belo de Jesus, Clóvis Lisboa Junior, Ludmyla Sathler Aguiar do Nascimento, \\ Edmar Reis Thiengo
}

Programa Educimat

Instituto Federal do Espírito Santo

Vitória, Espírito Santo

E-mail: thamiresbelo@yahoo.com.br,petclovis@hotmail.com,ludmylasathler@gmail.com, thiengo.thiengo@gmail.com

\begin{abstract}
Resumo: O presente artigo é fruto de pesquisas realizadas junto ao Grupo de Pesquisa de Educação Matemática, História e Diversidades, objetiva analisar a apropriação do conceito de número por alunos surdos do ensino fundamental da Educação de Jovens e Adultos (EJA) a luz da tendência da História da Matemática. Para isso será utilizada como metodologia de ensino uma sequência didática (SD). As atividades foram desenvolvidas com dois alunos surdos da EMEF Adevalni Sysesmundo Ferreira De Azevedo localizada no município de Vitória - ES. A história da matemática foi apresentada com o auxílio do intérprete e foram utilizados materiais concretos para que a reprodução dos fatos históricos ocorresse da forma mais fidedigna. A interação dos alunos surdos com os objetos concretos ocorreu de forma direta e indireta e o conceito de número foi trabalhado de forma dialogada entre o conhecimento científico apresentado pelos professores e pelo conhecimento prévio inerente aos alunos. Foram utilizados como principais aportes teóricos Centurión (2006), Skliar (2012) e Vygotsky (1984).
\end{abstract}

Palavras-chave: alunos surdos, história da matemática, educação matemática inclusiva.

\section{USE OF THE HISTORY OF MATHEMATICS IN THE CONCEPT OF OWNERSHIP NUMBER: A STUDY WITH THE DEAF STUDENTS EJA}

Abstract: This article aims to analyze the appropriation of the concept of number by deaf students of elementary school Education for Youth and Adults (EJA) the light of the trend of the History of Mathematics. To this will be used as teaching methodology teaching sequence (SD). The activities were developed with two deaf students of EMEF Adevalni Sysesmundo Ferreira de Azevedo in the municipality of Vitória - ES. The history of mathematics was presented with the help of interpreter and concrete materials were used for the reproduction of historical events occurred as accurately as possible. The interaction of deaf students with concrete objects was directly and indirectly and number concept was worked dialogue form between scientific knowledge presented by teachers and by students prior knowledge inherent. Were used as the main theoretical contributions Centurion (2006), Skliar (2012) and Vygotsky (1984).

Keywords: deaf students; history of mathematics; mathematics education inclusive.

Recebido em 26/09/2014. Publicado em 30/03/2016. 


\section{INTRODUÇÃO}

As reflexões expostas neste texto foram discutidas entre os autores que participam do Grupo de Pesquisa de Educação Matemática, História e Diversidades ${ }^{1}$. Vem ao encontro dos múltiplos olhares em relação ao ensino e aprendizagem de alunos surdos e ao uso da história da matemática como tendência ${ }^{2}$ de ensino. O cerne deste estudo concentra-se no sujeito surdo, nas suas experiências, potencialidades e dificuldades. Desta forma, iniciamos este estudo com abordagem da surdez enquanto marcas culturais.

Segundo Skliar (2012, p.11) “a surdez constitui uma diferença a ser politicamente reconhecida; é uma experiência visual; é uma identidade múltipla ou multifacetada". Visto isso, buscaremos transcender a abordagem surda do viés da patologia, ao considerá-lo diferente sob uma perspectiva visual e histórica. Além disso, o surdo constrói seu espaço cultural, principalmente por meio da Língua de Sinais, no caso dos surdos brasileiros, da Língua Brasileira de Sinais (LIBRAS), legalmente regulamentada pelo Decreto Lei $N^{\circ} 5.626$ em 2005. A respeito desta língua, Klein (2008, p. 2) afirma que:

A língua de sinais constitui-se como um dos traços identidários: as identidades dos sujeitos são construídas na língua e através dela. A diferença surda apresenta-se como uma construção histórica e social ancorada em práticas de significação e de representações compartilhadas entre os surdos. Os sentidos que os surdos dão a suas experiências constituem a sua cultura.

As palavras de Klein (2008) estabelecem um diálogo com Skliar (2005), à medida que ele afirma que "a linguagem possui uma estrutura subjacente independente da modalidade, seja esta auditivo-oral ou viso-gestual. Deste modo, a língua oral e a língua de sinais não constituem uma oposição, mas sim, canais diferentes para transmissão e a recepção da capacidade mental da linguagem".

\footnotetext{
${ }^{1}$ O Grupo realiza pesquisas na área da Educação Matemática envolvendo tanto aspectos históricos quanto os relacionados à inclusão, considerando-se a diversidade. Refletimos sobre as práticas pedagógicas realizadas em sala de aula que envolvem os aspectos inclusivos e os que atentam para a aprendizagem permeada pela tendência da história da matemática. O Grupo de Pesquisa é composto por professores e mestrandos do Instituto Federal do Espírito Santo.

${ }^{2}$ Aqui entendidas como formas de trabalho que surgem da busca de soluções para os problemas da Educação Matemática (FLEMMING; LUZ; MELLO, 2005, p.14), que são variadas e englobam jogos, modelagem, etnomatemática, informática, história da matemática, dentre outras.
} 
Frente ao exposto acima, destacamos que os surdos constroem sua caracterização como grupo cultural e linguístico e se definem pela identidade cultural marcada pela experiência visual. Apoiamo-nos em Sá (2005) para justificar esta identidade cultural almejada pelos próprios surdos. A autora afirma que "os surdos não querem ser chamados de 'deficientes' não por negarem delirantemente a surdez, mas por resolverem sua impossibilidade de apreender auditivamente o mundo por meio de uma leitura visual do mesmo" (p.76).

Diante deste cenário, deve-se pensar a educação dos sujeitos surdos que vá ao encontro do respeito por suas diferenças e que atenda suas necessidades, e isso vai além da criação de estratégias que objetivam que os surdos se adaptem a atividades ouvintistas. É preciso, conforme Skliar (2012) que a "escola procure ver os surdos dentro do hibridismo em que estão envolvidos enquanto sujeitos diferentes e pertencentes a um grupo cultural em permanente construção e desconstrução de conceitos, comportamentos, valores, etc." (p. 112).

Dentro do contexto da diversidade presente na sala de aula, precisamos, enquanto professor, visualizar a diversidade. E a partir deste momento, o professor terá condições de pensar em práticas pedagógicas que possibilitem o acesso de todos os diferentes ao conhecimento matemático. Se o professor não visualiza o aluno surdo em sua sala de aula, as suas práticas serão sempre pensadas a partir da maioria dos alunos. Desta forma, as diferenças são apagadas e as particularidades dos alunos são apagadas.

De igual forma, precisamos buscar trabalhar diversos conteúdos matemáticos com os alunos surdos, ou seja, práticas que se sustentam em um currículo não infantilizado e sem adaptações curriculares. Afinal, "os surdos estão cobrando da escola a aprendizagem dos conteúdos que a sociedade demanda para a inclusão de seus membros" (vieira-machado, 2010, p. 176).

Dentre as diversas estratégias capazes de potencializar as habilidades e experiências surdas, destacamos o uso da história da matemática como metodologia de ensino. Visto que, ao ter contato com os fatos e elementos que constituem a história de determinado conteúdo, o sujeito surdo terá a oportunidade de vivenciar estas criações e participar de forma ativa na construção de conhecimentos, visto que, segundo Buzar (2009) "é pela via do olhar que esses sujeitos desenvolvem sua mediação semiótica com o mundo". Além disso, faz-se necessário destacar a importância da linguagem e uso dos signos para a apropriação de conceitos dos sujeitos surdos e a 
importância da mediação dos signos para melhor apropriação dos fatos históricos referentes à Matemática. A esse respeito, utilizar-se-á a teoria Vygotskyana da linguagem e mediação para melhor entendimento deste processo de apropriação do conceito de número.

\section{FUNDAMENTOS TEÓRICOS}

Para este estudo foi delimitado o conteúdo de número, destacando sua criação histórica, necessidade de criação ao homem e, por conseguinte, a importância do ensino e aprendizagem deste tema. Para tanto, é preciso descrever qual conceito de número será trabalhado e um pouco de sua história.

Ao longo desenvolvimento do processo de contagem realizado pelo ser humano, é despertado no homem a noção de adição por meio do acréscimo de uma unidade ao total. Ou seja, a construção dos números naturais se dá pela recorrência da soma de uma unidade ao antecessor, caracterizando o sucessor deste. Quanto à ideia de subtração, a comparação de dois grupos distintos constitui uma das formas mais antigas para se perceber essa situação, quando no processo de comparação percebe-se a desigualdade e determina-se qual o maior.

Para Centurión (2006), a ideia de número nasceu da necessidade de se efetuarem contagens e da correspondência um-para-um que o homem foi estabelecendo entre vários conjuntos com a mesma quantidade de elementos. Assim, o número é uma qualidade que as coleções têm, que depende apenas da quantidade de seus elementos, independentemente da natureza dos objetos que as compõem. Isto é, quando duas ou mais coleções apresentam a mesma quantidade de objetos, associamos a ela o mesmo número. Podemos representar os números de maneira gráfica e oral, por meio de símbolos. Esses símbolos, que podem ser figuras ou palavras, são chamados de numerais. 
Figura 1: Representação de Números (Centurión, 2006, p. 19).

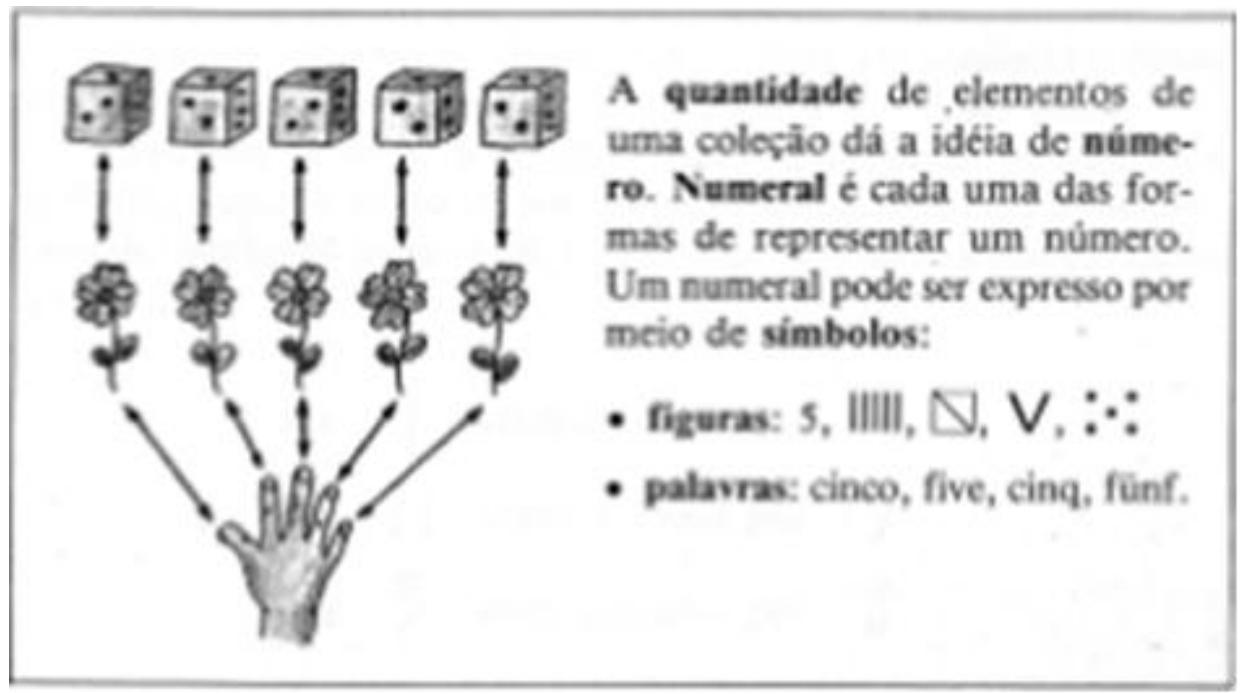

Neste caso podemos observar que Centurión (2006) apresenta diversas representações de quantidades de elementos que, por sua vez, dão a ideia de número, ou seja, diversas linguagens e signos para a representação de quantidades. Neste ponto a autora dialoga com Skliar (2005), à medida que este afirma que a linguagem possui uma estrutura subjacente independente da modalidade, seja esta visuo-gestual ou auditivo-oral. Este diálogo possibilita uma abordagem histórica dos diversos signos utilizados para representação de quantidades.

Entretanto, para investigarmos como se deu o processo de contagem precisamos recorrer aos historiadores que buscam indícios de apropriações das informações referentes às ideias de soma e subtração. Para tanto, os estudiosos analisam as ruinas de antigas civilizações, estudam fósseis, a linguagem escrita e a avaliam o comportamento de diversos grupos étnicos desde o princípio dos tempos. A partir destas evidências, compreendemos que o homem desenvolveu a estrutura lógica para o processo de contagem devido necessidades que emergiram com as atividades humanas, quando o homem foi deixar de ser pescador e coletor de alimentos para fixar-se no solo, desenvolvendo atividades agrícolas.

Um dos sistemas de numeração mais antigos que se tem notícia é o egípcio, uma civilização mesopotâmica que apresentava um grande desenvolvimento social, situada às margens do rio Nilo. Sua principal atividade econômica era a agricultura, a qual tiveram que aprimorar as técnicas utilizadas na colheita, armazenamento e distribuição de alimentos, bem como, a criação de métodos de agrimensura para a construção de canais e reservatórios e para dividir a terra e a 
instituição de práticas financeiras e comerciais para o lançamento e a arrecadação de taxas e para propósitos mercantis (EVES, 2011, p.57).

Assim, o conhecimento matemático produzido nessa época tinha um viés prático a serviço das atividades ligadas à agricultura e engenharia. A base usada no sistema de numeração hieroglífico egípcio e a 10. As representações simbólicas atribuídas para 1 e para as primeiras potências de 10 são as seguintes:

Figura 2. Símbolos numéricos egípcios (Eves, 2011, p.31)

\begin{tabular}{|ccc|}
\hline 10 & um bastio vertical \\
$10^{2}$ & uma ferradura \\
$10^{3}$ & 8 & um rolo de pergaminho \\
$10^{4}$ & 8 & um dedo de lótus \\
$10^{5}$ & umcurvado \\
$10^{6}$ & us barbato & um homem espantado \\
\hline
\end{tabular}

O cenário histórico exposto acima e a constituição cultural do sujeito surdo, com destaque a sua experiência visual e língua própria reconhecida, nos levam a caminhos possíveis para uma investigação no ensino e aprendizagem de matemática para alunos surdos a luz da tendência da história da matemática. Para isso faz-se necessário um maior aprofundamento no tema de linguagem e mediação, que será realizado neste estudo com as contribuições de Vygotsky.

\subsection{Vygotsky: linguagem e mediação}

A comunicação está presente em quase todo formato de linguagem, seja essa comunicação verbal, visual, gestual, computacional ou simbólica. Usamos as diferentes linguagens para nos colocarmos no mundo, expondo nossa cultura e lugar social que ocupamos. Nesses processos de representação simbólica de interagir homem, linguagem e representação do pensamento, a mediação se faz essencial para estimular o desenvolvimento da aprendizagem do aluno. 
No processo sócio-histórico do pensamento vygotskyano, a mediação pode se efetivar por intermédio da lembrança de situações semelhantes já vivenciadas pelo indivíduo. Desse modo, em nossa proposta de atividade vivenciada com os alunos surdos, buscamos por meio da história dos números fazer associações que pudessem mediar os conhecimentos já internalizados ampliandoos por meio das atividades propostas. A cerca destas ações, "Vygotysky trabalha com a noção de que a relação do homem com o mundo não é uma relação direta, mas fundamentalmente, uma relação mediada" (OLIVEIRA, p.29).

Nessa perspectiva há dois elementos mediadores: os instrumentos e os signos. O instrumento é tudo aquilo que marca o homem como espécie diferenciada e que no processo de formação cultural sofre a ação do homem transformando a natureza que o cerca. Já o signo, o que será mais evidenciado aqui, tem a função de auxiliar na resolução de problemas psicológicos como, por exemplo, fazer "lembrar, comparar coisas, relatar, escolher e etc." (VYGOTSKY, p. 59).

Desse modo ao apresentarmos na história da matemática signos associados a invenção de representações simbólicas que iniciaram com a contagem de pedras e evoluíram até a escrita dos numerais, estamos propondo a construção imagética da representação cognitiva dessa história para atribuir sentido para o aluno surdo do conceito do que é o número, como o representamos e de sua função social. Segundo Oliveira, sobre a teoria vygotskyana, a "memória mediada por signos é mais poderosa que a não mediada". Portanto, em nossa proposta buscamos ressaltar essa mediação como elemento fundamental para construção de relações significativas dos números e seus distintos signos, e a mesma foi aplicada para dois alunos surdos e será explicitada na seção seguinte.

\section{MATERIAIS E MÉTODOS}

Os sujeitos desta pesquisa constituem-se de dois alunos surdos, estudantes da EJA segundo segmento da escola EMEF Adevalni Sysesmundo Ferreira De Azevedo. Estes alunos frequentam a sala de aula regular, junto aos demais alunos ouvintes, no turno noturno, e no turno vespertino frequentam o atendimento especializado realizado pelos professores bilíngües e pelos intérpretes de Libras. Neste atendimento especializado os alunos recebem reforço escolar em relação ao 
conteúdo que está sendo tratado pelo professor regente no turno noturno, além de receber reforço escolar para atender as dificuldades referentes aos conteúdos elementares que se encontram defasados. Assim sendo, a sequência didática foi desenvolvida para atender as dificuldades em relação ao conceito de número. Foram utilizados alguns materiais pedagógicos para a realização desta sequência didática, quais sejam: pedras de tamanhos diferentes para representar as unidades, dezenas e centenas, software de apresentação de slides e imagens que representavam os fatos históricos referentes a história dos números.

Trata-se de um estudo de cunho investigativo e participante, com intervenção dos pesquisadores. Além de objetivar analisar o uso da história da matemática na apropriação do conceito de número pelos sujeitos surdos, este estudo visa explorar e conhecer os sujeitos surdos, além de suas formas de comunicação, interação com a matemática e sua relação com o intérprete de LIBRAS.

Os dados foram coletados por meio do diário de bordo dos pesquisadores, entrevista mediada pelo intérprete de LIBRAS, fotografias e registros sistemáticos. A analise dos dados foi baseada nas sustentações fornecidas por Skliar (2012), Oliveira (2010), Vygostky (1984) e Centurión (2006).

\section{DESENVOLVIMENTO}

A primeira etapa da sequência didática teve como objetivo estabelecer a diferença entre palavras, símbolos e algarismos, visto que, como a linguagem utilizada pelos surdos é visual necessita-se fazer uma distinção entre os diversos símbolos existentes e o seu significado. Foram utilizadas atividades conforme figura 4.

Um fato merece destaque nesta atividade; no item a o aluno substitui o símbolo pela palavra mãos. E quando foi questionado o aluno surdo afirmou que procedeu desta forma porque a quantidade 5 está no plural. Nesta dinâmica o aluno deveria descrever o sinal e fazer a datilologia de cada palavra. Constatamos que a maior dificuldade do aluno surdo foi realizar a datilologia das palavras, principalmente quando as palavras continham as letras, "q", "g". Em relação aos números, identificamos que os surdos possuem maior dificuldade quando a quantidade ultrapassa 30 unidades. 
Jesus e outros, 2016 - Ensino de Ciências e Matemática

Figura 4. Atividades - diferença entre palavra, símbolo e Algarismo.

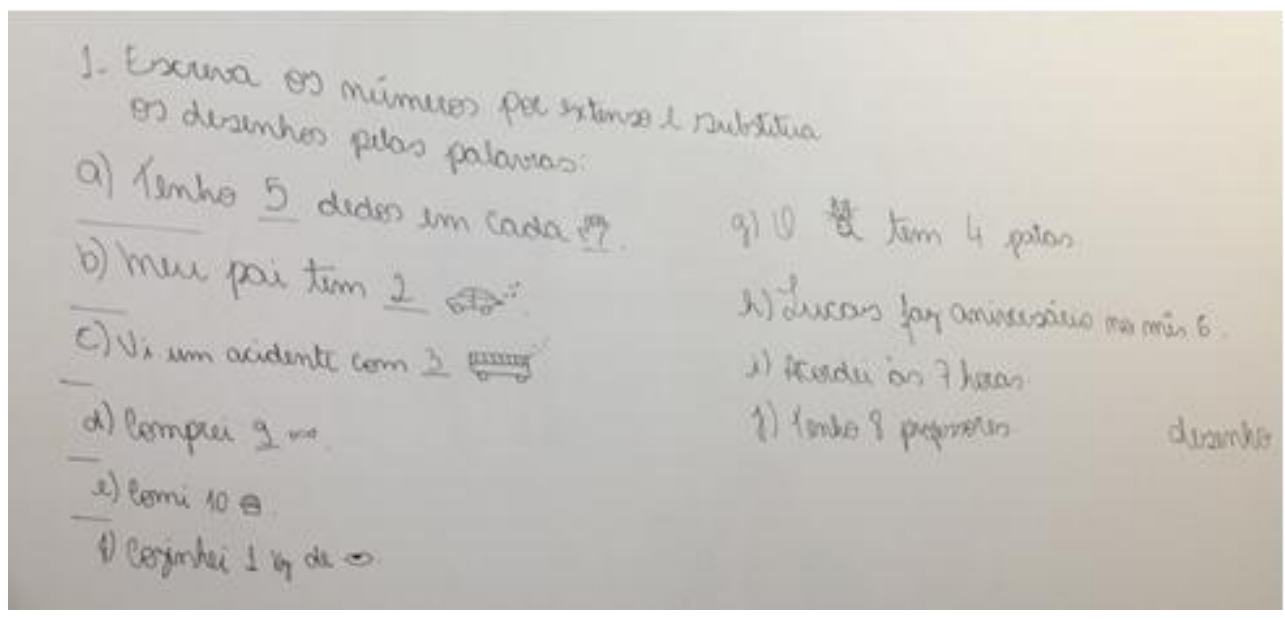

Posteriormente, nos reportamos à abordagem da História da Matemática para o desenvolvimento da dinâmica que visa contribuir com a apropriação do conceito de número pelos sujeitos surdos. Nesta etapa, contamos com auxílio da intérprete que traduziu a história para o surdo por meio da Libras. Foram utilizados materiais concretos para melhor significação da história dos números, e neste caso fizemos o uso de pedras de tamanhos diferentes para representar as unidades e dezenas.

Os elementos históricos utilizados foram baseados na fundamentação de Centurión (2006) e adaptados para a linguagem adequada aos surdos. A história retratava o pastor que contava suas ovelhas por meio de associações entre pedras-ovelhas. Sendo que a quantidade de ovelhas do pastor aumentava a cada processo de reprodução.

Figura 5. Representação do fato histórico.

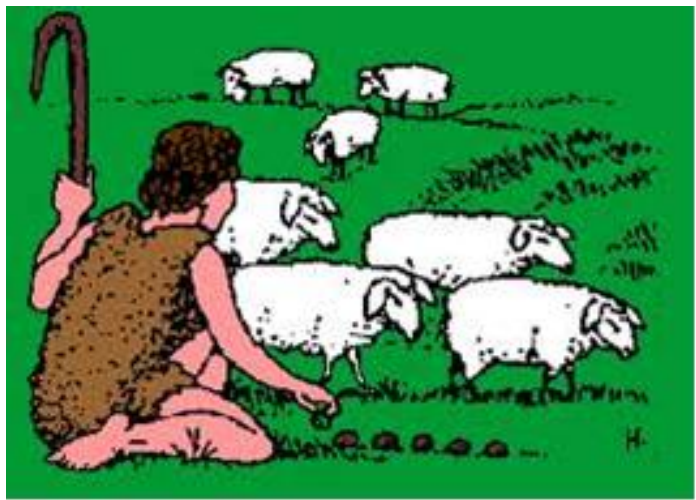

Figura 6. Processo agrupamento.

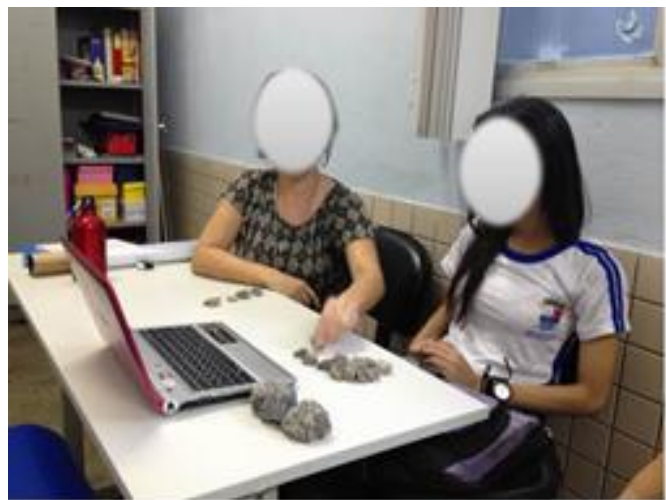


A história da matemática foi apresentada para os alunos com o auxílio de representações dos fatos históricos conforme figura 5, onde esta auxiliou a caracterização do cenário histórico, contribuindo como mediação simbólica para estimular a lembrança e relação entre o conceito de número e sua abordagem histórica. Durante a narração dos fatos, a aluna surda interagia com as pedras que representavam as unidades e fazia a contagem com o uso destes objetos. Até que chegou um momento da história em que a quantidade de ovelhas era tão grande que a quantidade de pedras tornou-se insuficiente para o processo de contagem. Neste momento da história a aluna surda expõe o seguinte pensamento "são muitas ovelhas e temos poucas pedras". Sendo assim, a professora iniciou a abordagem do processo de agrupamento.

Figura 7. Processo de agrupamento.

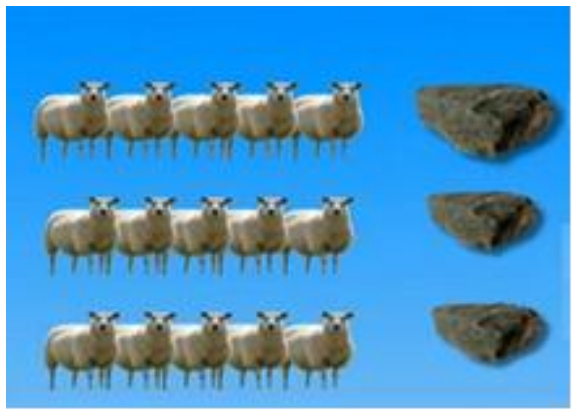

Figura 8. Agrupamento base 10.

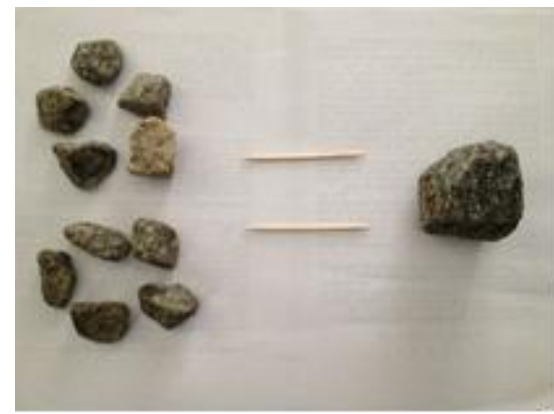

Diante deste contexto histórico, o pastor de ovelhas teve a necessidade de adequação do processo de contagem, tendo em vista a insuficiência de pedras para a realização do processo de contagem. É rico ressaltar que esta necessidade foi percebida pela aluna surda, sinalizando para uma interação e entendimento da abordagem histórica. Inicialmente o agrupamento iniciou-se com a junção de cinco unidades, conforme figura 7, posteriormente foi criado o agrupamento de dez unidades e, por conseguinte a estruturação da base dez. Vale ressaltar que o sinal de equivalência foi representado na imagem 8 por dois palitos, e o significado da palavra equivalência foi trabalhado com a aluna surda.

Após a criação da ideia de agrupamento foi discutida a necessidade de criação de símbolos para a representação de quantidades. Sendo que cada povo, culturalmente constituído, criou durante sua história, seus próprios símbolos. Os Egípcios criaram seus signos com base em sua cultura e necessidade, assim também fizeram os brasileiros ouvintes e brasileiros surdos, que criaram seus próprios signos para designar os algarismos, conforme figura 9. 
Figura 9. Simbologia surda e ouvinte.

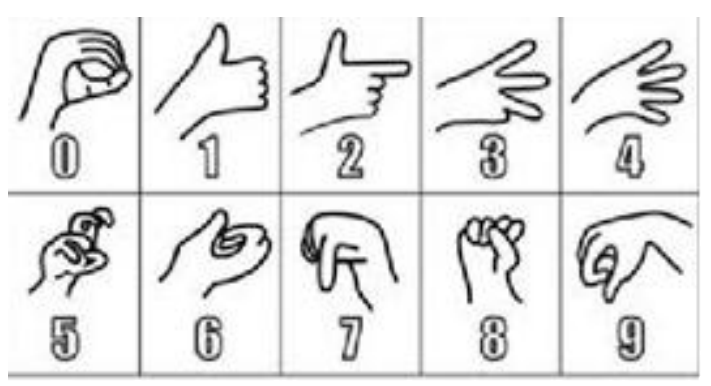

Após a abordagem que retratou um resgate histórico da criação dos números e a necessidade de criação de signos para representação de quantidades, iniciou-se uma entrevista mediada pelo intérprete com a aluna surda. Ao ser questionada sobre os possíveis locais que podemos encontrar os algarismos na linguagem ouvinte que fosse compatível com a linguagem surda, ela afirmou: "na mensagem do ônibus 883 que vai para minha casa, no número da minha casa, no número do telefone da minha casa e na idade das pessoas". Além disso, os sujeitos surdos destacaram a importância LIBRAS para melhor comunicação e entendimentos dos conteúdos matemáticos.

\section{CONSIDERAÇÕES FINAIS}

Em nossa proposta, sob a luz da teoria vygotskyana, buscamos ampliar o significado de número criando por meio de imagens relações significativas entre a história dos números e suas representações simbólicas, uma vez que para o surdo, essas construções imagéticas exercem grande função na construção do sentido e no processo de representação do símbolo, número, graficamente representado. Buscamos também fomentar os conhecimentos já internalizados e apresentados por nós, com o intuito de inter-relacionar tais significados para ampliar saberes nesse processo cognitivo constante. Constatamos que o uso da história da matemática foi um fator estimulante para melhor apropriação do conceito de número pelos sujeitos surdos, não só pelo viés conceitual, mas também pela possiblidade de melhor interação destes sujeitos com o processo de criação e desenvolvimento do conhecimento científico.

A mediação dos recursos pedagógicos utilizados desempenhou papel fundamental nesta abordagem, visto que apresentam grande proximidade com a experiência visual dos surdos, conforme assinalado por Skliar (2012). 
Nesse sentido, acreditamos que pesquisas envolvendo o ensino de matemática para alunos surdos a luz da história da matemática, podem contribuir fornecendo elementos para a melhoria das práticas pedagógicas inclusivas, além de abrir caminhos para novos estudos que venham contribuir com a inclusão de alunos surdos e maior divulgação da história da matemática como tendência de ensino.

\section{REFERÊNCIAS}

BUZAR, E.A.S. A singularidade visuo-espacial do sujeito surdo: implicações educacionais. Brasília, 2009. Dissertação de mestrado - Programa de Pós-Graduação em Educação, Faculdade de educação da Universidade de Brasília/UnB, Brasília, 2009.

CENTURIÓN, Marília. Conteúdo e metodologia da matemática: números e operações. 2ạ ed. São Paulo: Scipione, 2006.

EVES. Howard. Introdução à história da matemática. Tradução de Hygino H. Domingues. 5a ed. Campinas (SP): Editora da Unicamp, 2011.

KLEIN, M.; FORMOZO, D. P. Im/possibilidades na educação de surdos: discussões sobre currículo e diferença. Currículo sem Fronteiras, v. 9, n. 2, p. 212-225, 2008.

MOYSÉS, Lucia. Aplicações de Vygotsky à educação matemática. São Paulo: Papirus, 1997.

OLIVEIRA, Marta Kohl de. Vygotsky: aprendizagem e desenvolvimento: um processo sócio-histórico. 5 ed. São Paulo: Scipione, 2010.

VYGOTSKY, L.S. A formação social da mente. São Paulo: Martins Fontes. 1984.

PES, Ronaldo Bressan; FAJARDO, Ricardo; GARBERT, Rodrigo de Freitas. Sobre um estudo comparativo da subtração e divisão entre a matemática egípcia antiga e alguns livros didáticos. II Congresso Nacional de Educação Matemática, ljuí (RS), 2011.

SÁ, Nídia Regina Limeira. Cultura, poder e educação de surdos. Manaus: Editora da Ufam, 2002.

SKLIAR. Carlos. A Surdez: um olhar sobre a diferença. 6ạ edição. Porto Alegre: Mediação, 2012.

SKLIAR, Carlos; QUADROS, Ronice. Invertendo epistemologicamente o problema da inclusão: os ouvintes no mundo dos surdos. Estilos da clínica, São Paulo, v. V, n. 9, p. 32-51, 2005. 